\title{
CYATHOMYRMEX, A NEW NAME FOR THE SUBGENUS CYATHOCEPHALUS EMERY.
}

\section{By William Steel Creighton,}

Dept. of Biology, College of the City of New York.

The purpose of this note is to call attention to the existence of a synonym in the case of the generic name Cyathocephalus. This name was first used by the helminthologist Kessler in 1868 and repeated as the name of a subgenus of ants by Emery in 1915. With several excellent compilations of generic names at the disposal of the taxonomists it is surprising that the repetition has escaped detection for a period of almost eighteen years. The history of this synonym is instructive since it is a perfect example of the evils arising from what may be called a buried subgenus. It is obvious that the task imposed upon the compilers of generic and subgeneric lists is yearly growing more onerous. In justice to the men who have undertaken this herculean labor as well as for the sake of their own subject taxonomists should bend every effort to make the names of new subgenera as prominent as position and typography will permit. The present case demonstrates how easily confusion can arise when this practice is not followed.

In 1868 Kessler erected the genus Cyathocephalus to include a single species of a Cestode worm previously described by Pallas (1781) under the specific name truncatus. Kessler's work appeared in Russian in the Proceedings of the Russian Naturalists Society of St. Petersburg. Because of linguistic difficulties or, as seems more probable, because of the great rarity of the early issues of this periodical Kessler's description did not come to the attention of the compilators for a number of years. The first standard compilation to list the genus Cyathocephalus seems to have been Bronn's Klassen und Ordnungen des Tier Reichs. In 1894 this publication carried a reference to a paper by Brauns in which the genus was mentioned. Four 
years later the genus Cyathocephalus appeared in the Zoological Record, this time having been brought to light by Riggenbach when he described a second species in the genus. It is natural to suppose that the name Cyathocephalus would have been listed in the Record's Index of Genera covering the period from 1891 to 1900. Actually it occurs in the Index for 1901 to 1910 . The genus does not, of course, appear in Sherborn's Index Animalium since at present this colossal publication deals only with descriptions made prior to 1850. Heider includes Kessler's Cyathocephalus in his Nomenclator Animalium citing Braun's paper as his source. I am at a loss to account for the absence of Emery's synonymic subgenus in this publication for, as will be subsequently shown, there is no reason for the omission of the subgenus Cyathocephalus in any list made after 1921.

So much for the taxonomic history of the original Cyathocephalus. Let us now consider the case of Emery's synonym. In 1915 Emery published a brief paper in the Bulletin of the Entomological Society of France entitled "Names of Subgenera and Genera proposed for the Subfamily Myrmicinae." In an explanatory preface Emery states that the paper presents a summary of work prepared for inclusion in Wytsman's Genera Insectorum. At that time this publication had been suspended on account of the World War and it is easy to appreciate Emery's anxiety to get his work into print. It may be questioned, however, that any circumstances justify the means which he took to insure the priority of his classification. In his paper, three pages in length Emery established eleven new subgenera. Five of these were delimited at least by a line or two of description but the remaining six were set up by simply designating a type. Emery's position was, nevertheless, technically secure since all of his subgenotypes were previously described species. Regardless of what attitude we take as to the propriety of this procedure there can be no question that Emery made a serious mistake by incorporating the names of six of his new subgenera in the text of the article in such a manner that it is virtually impossible to discover their existence. Nor does Emery's culpability end 
here since, through oversight, he used the name Cyathocephalus for one of his new subgenera. As has already been shown this name was present in two standard compilations prior to the year 1915. There is, consequently, no way in which Emery could have justified his repetition of the name.

Emery's paper was duly entered in the Zoological Record for 1915 and it is interesting to see what they made of it. Three of the subgenera were prominently placed in a key and noted as new in bold face type. Immediately following this key were two line descriptions of two more new subgenera which were also noted in bold face. All five of these are listed in the index of the Zoological Record for the year 1915. The remaining six subgenera were incorporated in several short paragraphs which together total slightly more than three hundred words. Of these seventy-nine are italicized. To make matters worse the italics may be specific, generic or tribal names and in one case they refer to a publication. Is it any wonder, since Argus could not be called to the aid of the compilators, that the names of the six new subgenera escaped notice? It may be said in Emery's defense that his masterly treatment of the Myrmicinae in the Genera Insectorum, when that section was published in 1921, does much to condone this rare lapse from taxonomic grace. At the same time it cannot be too strongly stressed that the practice of embodying the names and description of new subgenera as a part of the text is pernicious in the extreme. The very facility with which this can be done, especially if the subgenotype is one of previous description, makes it especially dangerous.

There remains the duty of assigning a new subgeneric name to replace Emery's synonym. With a view to minimizing the change and retaining a term which is very aptly applied to the curious, cup-headed workers of this group I propose the following alteration:

Subgenus Cyathomyrmex nomen novum, to replace the synonymic subgenus Cyathocephalus Emery. The subgenotype Cryptocerus pallens Klug, the subgeneric characteristics as delimited by Emery in the Myrmicine section of the Genera Insectorum. 

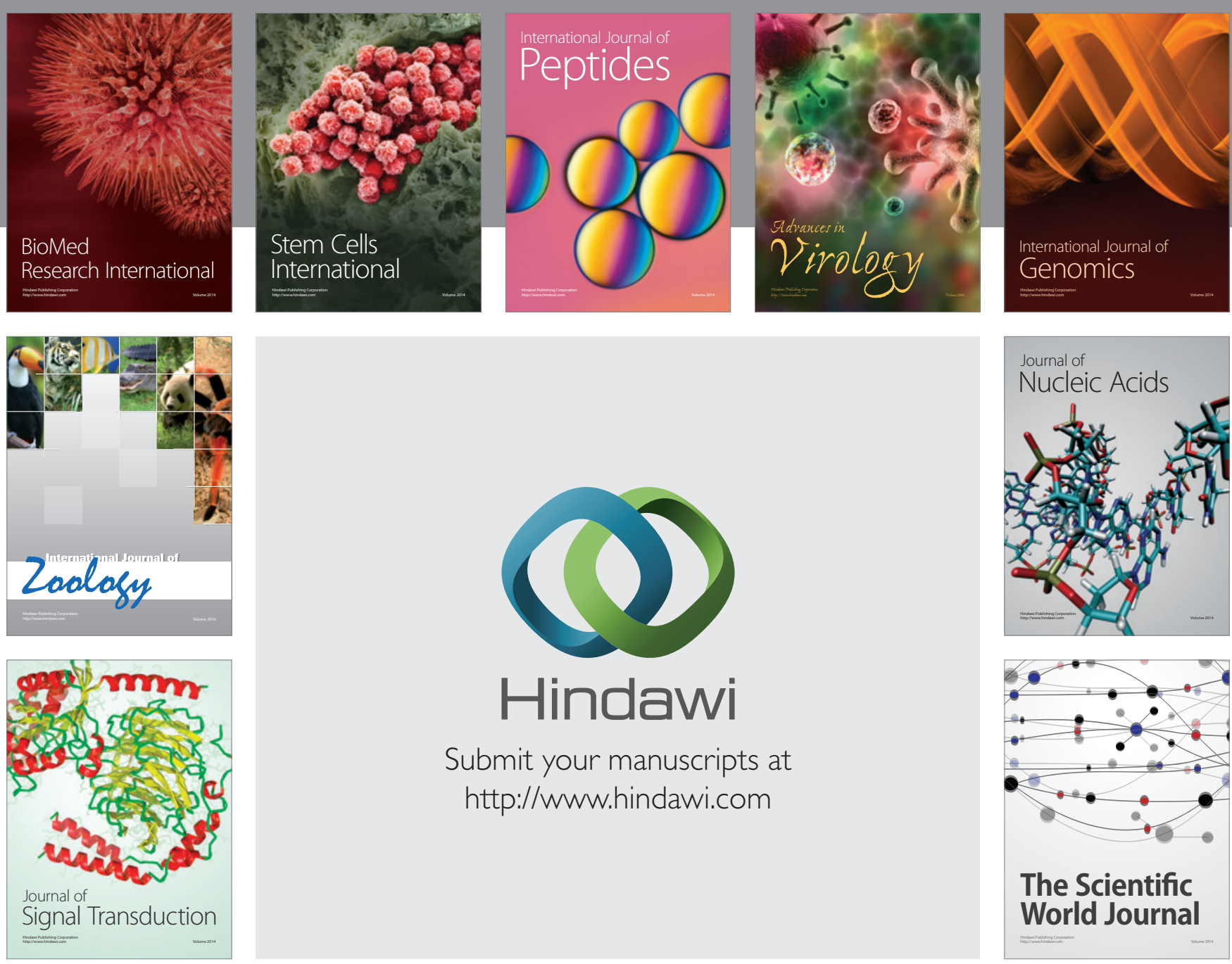

Submit your manuscripts at

http://www.hindawi.com
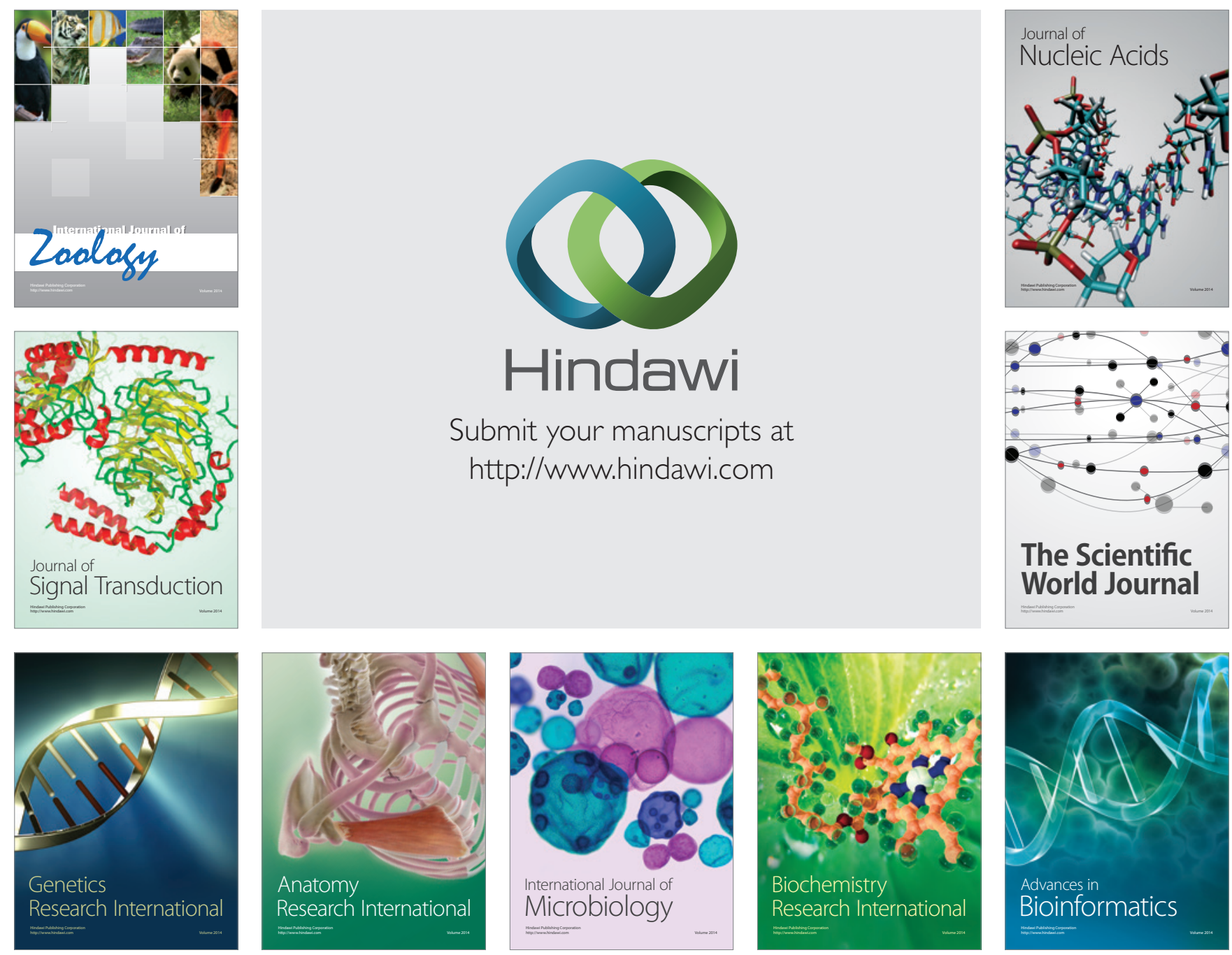

The Scientific World Journal
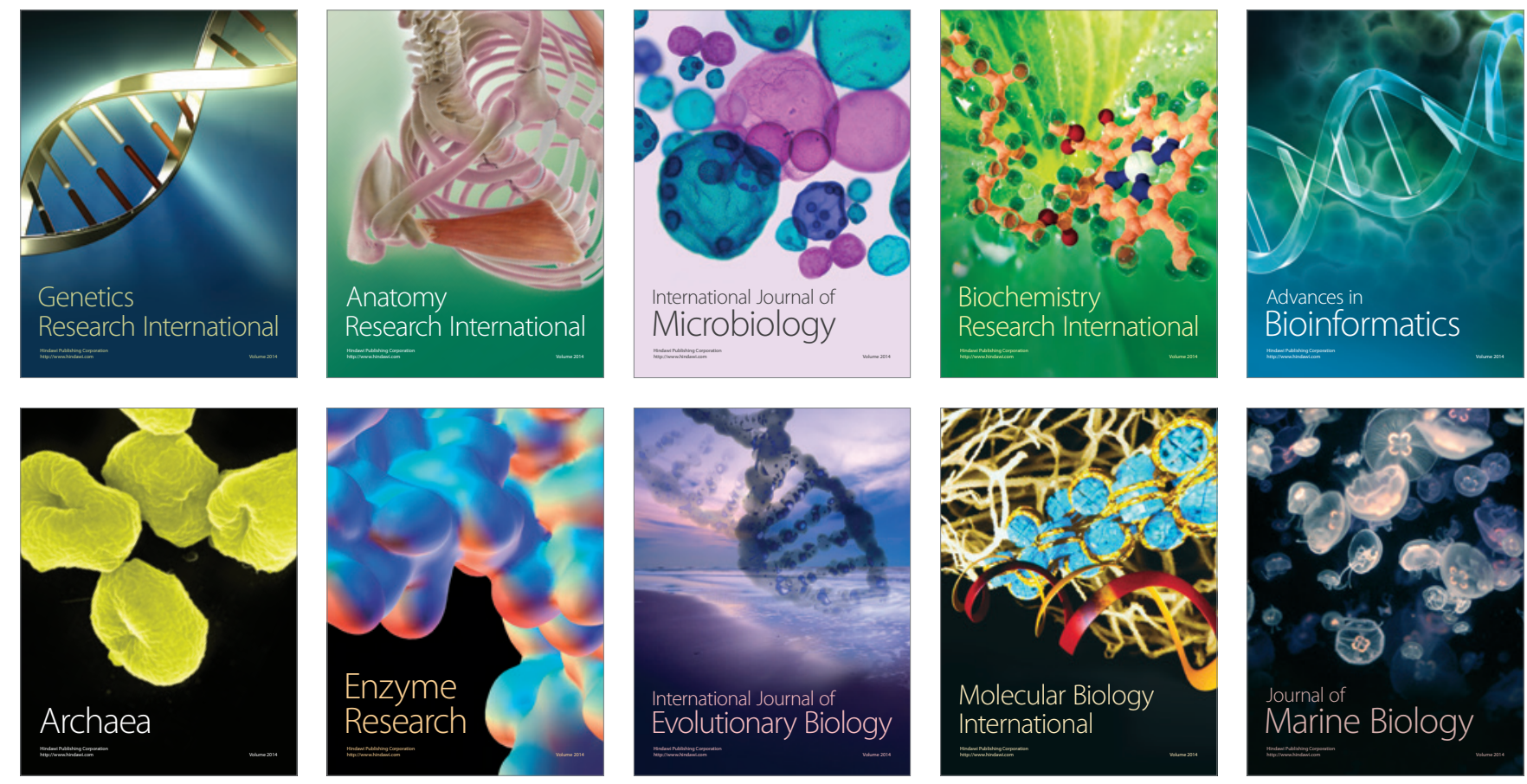